\title{
Practical application of climate-induced projected changes in water availability to underpin the water planning process in Victoria, Australia
}

\author{
D. A. Post ${ }^{a}$ and R. J. Moran \\ ${ }^{a}$ CSIRO Land and Water, GPO Box 1666, Canberra, ACT. David.Post@,csiro.au \\ ${ }^{b}$ Department of Sustainability and Environment, Victoria, Melbourne, Vic.
}

\begin{abstract}
Numerous climate change studies have recently, and are currently, being carried out across many regions of the world. However, is there sufficient confidence in the outputs of global climate models (GCMs) to make use of their projections at a regional scale; and secondly, if these results are to be used, how can researchers make the data directly usable by water managers?
\end{abstract}

This paper shows results from a water availability study recently carried out across south-eastern Australia, and demonstrates how the results of this study were used by water resource managers in the State of Victoria in far southern south-east Australia. Across Victoria, there is a near unanimous agreement among climate model outputs of the direction of change of future rainfall, with 14 of the 15 AR4 GCMs examined projecting a reduction in rainfall across this region. Additionally, as these reductions in rainfall are quite high over the major runoff-generating areas, reductions in runoff (and therefore water availability) are also projected across the vast majority of the State.

Climate change projections for this region were summarised by creating 'dry', 'wet' and 'median' future water availability scenarios for 2030 and 2060 based on results from the $2^{\text {nd }}$ driest, $2^{\text {nd }}$ wettest and $8^{\text {th }}$ wettest (or driest) GCM. These results were then averaged across 27 catchments covering the State of Victoria so that they could easily be used by urban and rural water corporations in their future water planning.

Of the 27 catchments covering Victoria, reductions in annual water availability (relative to the long term historical average) are projected for all 27 under both the 'dry' and 'median' future climate scenario for both 2030 and 2060 . For the dry future scenario for 2030, projected reductions in water availability range from $18 \%$ to $34 \%$, while for 2060 , the reductions range from $34 \%$ to $58 \%$. For the median future climate scenario, for 2030 , reductions in water availability range from $8 \%$ to $22 \%$, and $9 \%$ to $36 \%$ in 2060 . Under the 'wet' future climate scenario, only 5 catchments project an increase in water availability for 2030 and 2060. These catchments are located in the far north and east of the State. The remaining 22 catchments project reductions in water availability of up to $11 \%$ by 2030 and $19 \%$ by 2060 .

These results have been used in defining a range of plausible water availability futures which Victorian water corporations are using in preparing updated Water Supply-Demand Strategies for all the supply systems that they manage. These strategies aim to balance supply and demand over the next 50 years.

The reductions in water availability projected under the dry climate change scenario by 2060 are smaller than the reductions in water availability experienced during the recent drought (1997-2009) across much of the State. As climate research has shown that this drought appears to be at least partly linked to global warming, a future scenario based on a return to the dry conditions of the recent drought (1997-2009) in the short-term has also been included in the planning process.

In those regions where there is near-unanimous agreement among GCMs as to the direction of climate change impacts on rainfall, projected changes in water availability can be used by water resource planners to assist them in better planning for future changes in supply. Even then however, climate researchers and hydrologists must work closely with water managers to ensure that the information is provided in a usable way.

Keywords: $\quad$ Climate change, water availability, research adoption. 


\section{INTRODUCTION}

Deriving changes in future water availability based on climate change projections has become one of the more fruitful areas of research for hydrologists in recent years. Numerous papers have recently been published examining the impacts of climate change on water availability at many locations around the world. In south-eastern Australia alone, there have been a plethora of recent studies. Examples include Chiew et al. (2009), Post et al. (In Press), Sun et al. (2011), Vaze and Teng (2011) and Vaze et al. (2011).

Recently however, the usefulness of these studies for water management has been called into question (Kundzewicz and Stakhiv, 2010). Beven (2011) argues that the current generation of global climate models (GCMs) is not sufficiently robust to be able to be used to produce climate change projections which are useful for water managers. While we agree that there are issues with the quality of climate change projections, in locations where the vast majority of GCMs have a consistent sign in their projected changes in rainfall, this information is of use to water managers and should not be discarded. This is the case across the State of Victoria in south-eastern Australia, where 14 of the 15 AR4 GCMs with archived projections of daily data agree that rainfall is likely to decrease under one degree of global warming, and that even under the wettest of future climate projections, runoff across the high-yielding catchments north-east of Melbourne is likely to decrease by 2030 (Chiew et al., 2009). Additionally, these projections of decreasing rainfall are supported by recent research investigating the key drivers of rainfall across south-eastern Australia (CSIRO, 2010b).

Kiem and Verdon-Kidd (2011) argue that there is currently a gap between what climate science can provide and the needs of water managers. This is no doubt true if the "needs" of water managers are defined by the information they would like to have for the planning and management of their water supplies. What water managers would like are series of plausible climate and streamflow data at a regional scale that combine the influences of natural climate variability and climate change (and from which realistic estimates of changes in extremes can be derived). Ideally such data series would characterise plausible alternate futures extending from 'now' to some specified future point in time. This is clearly not possible at the present time, and indeed may never be. While advances in climate science can be expected to lead to improved and, therefore, more useful, projections, this will take time, and significant uncertainties will remain. As a consequence, there is a (often neglected) need for water managers to understand the nature and limitations of the information that is available and to determine how to make best, and appropriate, use of this information,. We would suggest that the natural link between climate scientists and water managers can occur through the hydrological community. The current paper provides an example of how this might be achieved through research carried out as part of the South Eastern Australian Climate Initiative (SEACI), which brings together climate scientists, hydrologists and water managers to find common ground over such issues. In the current paper, we show how changes in water availability as derived from climate change projections are being used in the water planning processes being implemented by the Victorian Department of Sustainability and Environment.

\section{METHODS}

Six projections of future climate, representing wet, median and dry future projections for the years 2030 and 2060 were derived. The steps used to obtain these projections are summarised here and more detail can be found in Chiew et al. (2009). Firstly, the likely change in global average surface air temperature was derived for 2030 and 2060. Based on the A1B emission scenario, these are estimated to be $1{ }^{\circ} \mathrm{C}$ for 2030 and $2{ }^{\circ} \mathrm{C}$ for 2060 (IPCC, 2007). Archived monthly simulations from 15 IPCC AR4 GCMs (see Post et al. (In Press) for the list of models used) were analysed to estimate the change in rainfall and other climate variables per degree of global warming. Each GCM was analysed separately. Data from each of the four seasons were also analysed separately.

The percent changes in the climate variables per degree of global warming for each of the four seasons from the 15 GCMs were then multiplied by the projected change in temperature for 2030 and 2060 to obtain 15 sets of 'seasonal scaling' factors for 2030 and 2060. These seasonal scaling factors were then used to scale the historical daily climate data from 1895 to 2009 to obtain 15 future climate variants, each with 114 years of daily climate data. The historical daily climate data were derived from the SILO Data Drill of the Queensland Department of Environment and Resource Management (Jeffrey et al., 2001) on a $0.05^{\circ}$ grid over the entire region.

Projections of changes in daily rainfall amounts were also taken into account by scaling different daily rainfall amounts by different factors using the 'daily scaling' methodology of Chiew et al. (2009). In general this led to projected increases or little change in large daily rainfalls and decreases in small and medium daily rainfalls for both 2030 and 2060 climate. 
The overall approach therefore scales the 114 years of historical daily climate sequence to represent the future daily climate sequences for 2030 and 2060. The scaling considers changes in the seasonal mean rainfalls and daily rainfall distributions informed by projections from 15 IPCC AR4 GCMs, although it does not account for changes in the sequencing of rainfall events.

Having derived the future climate sequences, these were then used as inputs to the SIMHYD rainfall-runoff model to produce future runoff projections. SIMHYD was chosen from a suite of five rainfall-runoff models as it produced the best calibration, and temporal and spatial cross validation results across southeastern Australia, although the difference to the results of other models was minimal (Viney et al., 2009). While runoff was modelled at $\sim 5 \mathrm{~km}^{2}$ resolution, given the uncertainties associated with the projections and their application (see Section 4), it was considered appropriate to average results at a catchment scale These projections of change in runoff (here assumed equivalent to water availability) were therefore averaged over 27 catchments (primarily defined by AWRC river basins) covering the State of Victoria (Figure 1).

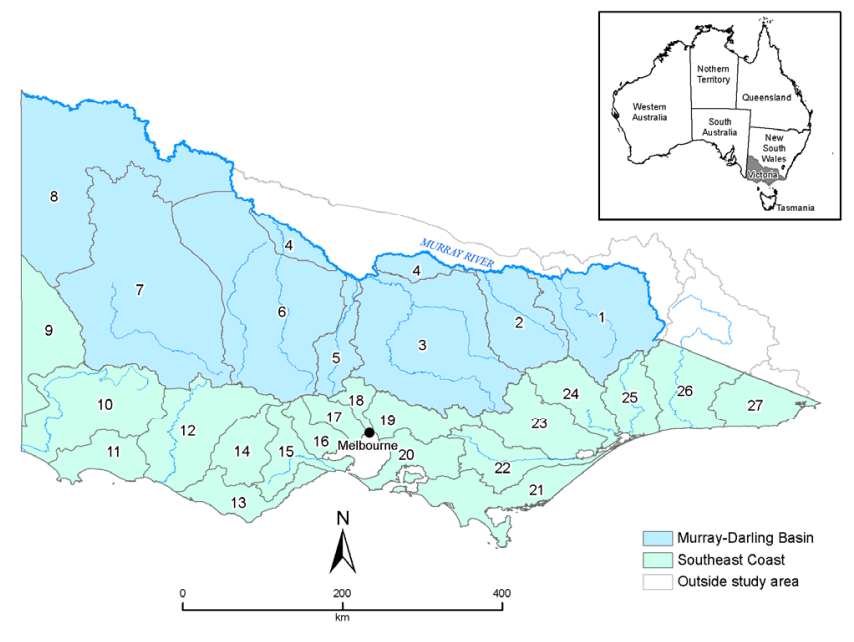

Figure 1. Location of the 27 catchments across Victoria for which changes in water availability were derived. Numbers refer to the catchments as listed in Table 1.

\section{RESULTS}

\subsection{Spatial results}

The change in runoff across south-eastern Australia for the wet, median and dry projections for 2030 are shown in Figure 2. Note that because of the technique used, the results for 2060 representing $2{ }^{\circ} \mathrm{C}$ of global warming are approximately double those shown in Figure 2. This will be explored further in the following section.

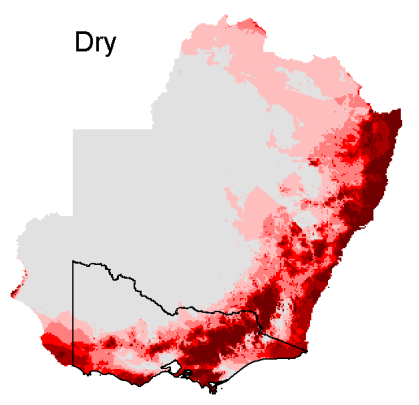

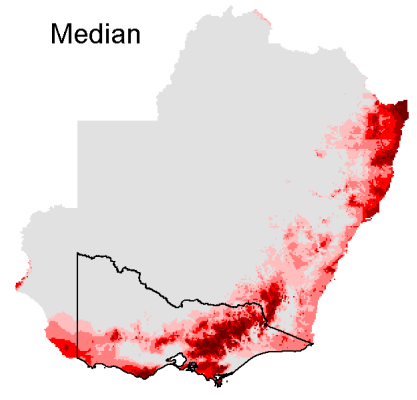

Change in annual runoff $(\mathrm{mm})$

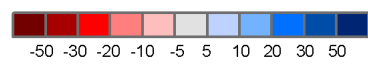

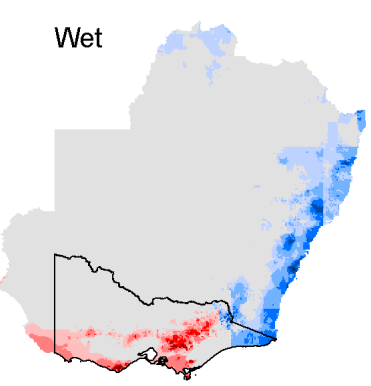

Victorian border

Figure 2. Change in mean annual runoff $(\mathrm{mm})$ for the 2030 wet, median and dry future climate projections. 
It will be seen from Figure 2 that even under the wet future projection, runoff is projected to decrease across most of Victoria with the exception of the far eastern part. Under the median and dry future projections, reductions in runoff are projected for most of the State, with no increases projected anywhere.

\subsection{Catchment-averaged changes in water availability}

These data are shown for all 27 catchments across Victoria in Table 1. As discussed above, for the median and dry future projections, reductions in runoff are projected for all catchments in Victoria. Even under the wet future projection, increases in runoff are only seen for five catchments (those in the north and east of the State).

Although the 2030 projections are derived based on $1{ }^{\circ} \mathrm{C}$ of global warming and those for 2060 are based on $2{ }^{\circ} \mathrm{C}$ of global warming, and the scaling technique used was linear for changes in rainfall (ie changes in rainfall for $2{ }^{\circ} \mathrm{C}$ are double those for $1{ }^{\circ} \mathrm{C}$ ), the changes in runoff do not scale linearly. Rather the changes for 2060 are slightly wetter than would be expected based on the projected changes for 2030 . This is due to non-linearities in the rainfall-runoff relationship and is discussed in Post et al. (2011).

Table 1. Projected percentage change in mean annual runoff for Victorian catchments for 2030 and 2060

Year

Catchment

1. Upper Murray

2. Ovens

3. Goulburn-Broken

4. Murray Riverina

5. Campaspe

6. Loddon-Avoca

7. Wimmera

8. Lower Murray

9. Millicent Coast

10. Glenelg River

11. Portland Coast

12. Hopkins River

13. Otway Coast

14. Lake Corangamite

15. Barwon River

16. Moorabool River

17. Werribee River

18. Maribyrnong River

19. Yarra River

20. Bunyip River

21. South Gippsland

22. Latrobe River

23. Thomson River

24. Mitchell River

25. Tambo River

26. Snowy River

27. East Gippsland
2030

\begin{tabular}{llllll} 
Wet & Median & Dry & Wet & Median & Dry \\
$0 \%$ & $-9 \%$ & $-19 \%$ & $0 \%$ & $-16 \%$ & $-36 \%$ \\
$-2 \%$ & $-13 \%$ & $-20 \%$ & $-4 \%$ & $-23 \%$ & $-38 \%$ \\
$-3 \%$ & $-12 \%$ & $-21 \%$ & $-5 \%$ & $-21 \%$ & $-38 \%$ \\
$10 \%$ & $-13 \%$ & $-27 \%$ & $21 \%$ & $-22 \%$ & $-45 \%$ \\
$-7 \%$ & $-16 \%$ & $-27 \%$ & $-13 \%$ & $-28 \%$ & $-48 \%$ \\
$-7 \%$ & $-17 \%$ & $-29 \%$ & $-12 \%$ & $-29 \%$ & $-48 \%$ \\
$-7 \%$ & $-19 \%$ & $-31 \%$ & $-12 \%$ & $-32 \%$ & $-52 \%$ \\
$10 \%$ & $-7 \%$ & $-23 \%$ & $23 \%$ & $-9 \%$ & $-38 \%$ \\
$-10 \%$ & $-18 \%$ & $-34 \%$ & $-19 \%$ & $-33 \%$ & $-58 \%$ \\
$-10 \%$ & $-18 \%$ & $-31 \%$ & $-19 \%$ & $-34 \%$ & $-54 \%$ \\
$-12 \%$ & $-16 \%$ & $-22 \%$ & $-19 \%$ & $-29 \%$ & $-40 \%$ \\
$-11 \%$ & $-22 \%$ & $-30 \%$ & $-19 \%$ & $-36 \%$ & $-50 \%$ \\
$-7 \%$ & $-15 \%$ & $-18 \%$ & $-14 \%$ & $-27 \%$ & $-34 \%$ \\
$-10 \%$ & $-20 \%$ & $-24 \%$ & $-16 \%$ & $-33 \%$ & $-42 \%$ \\
$-8 \%$ & $-18 \%$ & $-21 \%$ & $-14 \%$ & $-31 \%$ & $-37 \%$ \\
$-7 \%$ & $-16 \%$ & $-25 \%$ & $-12 \%$ & $-28 \%$ & $-41 \%$ \\
$-6 \%$ & $-16 \%$ & $-25 \%$ & $-11 \%$ & $-27 \%$ & $-44 \%$ \\
$-7 \%$ & $-16 \%$ & $-27 \%$ & $-12 \%$ & $-29 \%$ & $-47 \%$ \\
$-5 \%$ & $-13 \%$ & $-22 \%$ & $-8 \%$ & $-24 \%$ & $-38 \%$ \\
$-5 \%$ & $-14 \%$ & $-20 \%$ & $-8 \%$ & $-26 \%$ & $-36 \%$ \\
$-6 \%$ & $-12 \%$ & $-22 \%$ & $-9 \%$ & $-23 \%$ & $-40 \%$ \\
$-6 \%$ & $-14 \%$ & $-21 \%$ & $-8 \%$ & $-26 \%$ & $-37 \%$ \\
$-3 \%$ & $-13 \%$ & $-20 \%$ & $-5 \%$ & $-23 \%$ & $-35 \%$ \\
$-2 \%$ & $-11 \%$ & $-20 \%$ & $-3 \%$ & $-20 \%$ & $-36 \%$ \\
$2 \%$ & $-11 \%$ & $-24 \%$ & $5 \%$ & $-20 \%$ & $-42 \%$ \\
$11 \%$ & $-9 \%$ & $-22 \%$ & $21 \%$ & $-18 \%$ & $-40 \%$ \\
\hline $11 \%$ & $-8 \%$ & $-19 \%$ & $22 \%$ & $-15 \%$ & $-35 \%$ \\
\hline & & & & & \\
\hline
\end{tabular}




\section{APPLICATION OF THE PROJECTIONS}

Water supplies in Victoria are managed by 15 regional water corporations, Melbourne Water, and three Melbourne retail water businesses. Of the regional corporations, 11 are responsible for urban water supplies, two for rural supplies and two manage both urban and rural supplies. In order to ensure reliable water supplies now and into the future, the water corporations are required by Government to develop Water Supply-Demand Strategies (WSDSs) for each of the supply systems they manage. These WSDSs are aimed at balancing supply and demand over a 50-year time frame. The WSDSs then feed into the development of broader Regional Sustainable Water Strategies in a consultative process coordinated by Government. Complementing these long-term strategies, there is a range of planning and management tools that water corporations are required to develop for managing supplies in the short-term in response to periods of water shortage. At the end of spring each year (the end of the traditional recharge season), based on the supply position and the forward outlook, corporations are required to make judgements as to whether they need to implement any of the components (supply augmentation/demand reduction) of their short- or long-term strategies in order to maintain an acceptable supply reliability.

WSDSs were first developed in a consistent way by all water corporations across the State in 2006, and they are required to be reviewed every five years, thus this process is being undertaken in 2011. The development of the WSDSs is informed by guidelines which among other things include the specification of the range of plausible future climate/streamflow scenarios to be considered in the planning process.

As 2006 saw record low rainfalls and streamflows across the State after what was already nine years of drought, an additional scenario based on a continuation of the conditions of the last 10 years was also included in the WSDS planning process. This was the most challenging scenario to plan for, as observed reductions in streamflow over the period 1997-2006 were of the order of, or greater than, medium to high climate change projections by 2060 .

In developing the guidelines for the updated WSDSs in 2011, a key consideration was again defining the range of plausible climate futures to be considered. While the long drought of 1997-2009 has been broken by above average rainfalls across most of the State in the spring/summer of 2010/11, it is not at all certain that this signals a return to more 'normal' climatic conditions. The wet conditions were a result of the combination of influences from one of the strongest La Nina events on record, a negative Indian Ocean Dipole event, and a positive Southern Annular Mode over spring/summer. However, SEACI research (CSIRO, 2010a, 2010b) has shown that the recent drought appears to be at least partly linked to global warming through an intensification of the sub-tropical ridge. The intensification of this ridge means that the low pressure systems and frontal systems embedded in the westerly wind belt to the south of Australia tend to be pushed further south, resulting in a reduction in Victoria's previously relatively reliable late autumn/winter rainfall. Kent et al. (Submitted) have shown that these trends are likely to continue. This is consistent with Frederiksen et al. (2011) showing a general reduction in winter storminess across the midlatitudes which also appears to be linked to global warming.

In the light of these findings, while natural variability will continue to be a major influence, on balance the evidence suggests that a return to dry conditions cannot be discounted as being a possibility, perhaps even in the short to medium term. Therefore, in developing updated WSDSs in 2011, water corporations have been asked to explore the implications of four future water availability scenarios - the dry, median and wet climate runoff projections outlined above for 2030 and 2060 respectively, and a 'return to the dry conditions of 1997-2009' scenario. The detailed rationale and methodology for deriving the range of plausible future scenarios is set out in a Technical Supplement to the guidelines (Moran and Sharples, 2011).

The climate change projections described above are derived as percentage changes relative to $\sim 1990$ conditions. As was the case in 2006, the full historic streamflow record has again been chosen as the baseline to which to apply the projections, because it is not yet possible to attribute the relative contributions of climate change and natural variability in the recent streamflow record.

Further, because emissions are currently tracking between the marker scenarios for the A1B and A1FI emission scenarios (Manning et al, 2010), water corporations have also been asked to consider the implications of the possible earlier attainment of a $1{ }^{\circ} \mathrm{C}$ and $2{ }^{\circ} \mathrm{C}$ warming. Based on the IPCC (2007) estimates of the trajectories of warming (and associated uncertainties) under both the A1B and A1FI emissions scenarios, a $1{ }^{\circ} \mathrm{C}$ warming could be attained as early as around 2025 , and $2{ }^{\circ} \mathrm{C}$ by around 2043 .

In deciding how to utilise the climate change projections, it is important to acknowledge the uncertainties associated with the projections, but without letting these uncertainties undermine any robust findings about regional climate change. A key source of uncertainty in projected mean annual runoff is associated with the 
selection of the baseline for the projections given the high natural variability of streamflow. For Victoria, this is likely to be of similar magnitude to that associated with GCM selection. For example, a 30-year moving average (a typical length for defining a climatologic baseline) of inflows to Lake Eildon varies over time between about $+19 \%$ to $-15 \%$ of the long-term average. The projected wet, dry and median changes in runoff for 2060 are $-5 \%,-21 \%$ and $-38 \%$ respectively, with the dry projection of $-38 \%$ being less than the observed reduction in flow (-41\%) during the recent drought (1997-2009). This issue regarding the selection of an appropriate baseline remains a problematical one in the application of climate change projections in Victoria, and further attribution research being conducted as part of SEACI should be of assistance in determining the extent to which a climate change signal is already present in the streamflow record.

As was the case in 2006, the 'return to dry scenario' is the most challenging to plan for in the 2011 WSDSs as the observed reductions in streamflows over 1997-2009 are greater than the dry climate change projections for 2060 across most of the State, the exception being in the higher rainfall areas along the Great Dividing Range where the observed reductions in flow are closer to the median projections for 2060. This suggests that if water planning processes are aimed at coping with a 'return to dry' conditions in the short to medium term, they should be able to cope with even the dry climate change projections projected for 2060 .

\section{DISCUSSION AND CONCLUSIONS}

It is fair to say that the climate change projections that are currently available (even with detailed downscaling) are not what water managers would like to have. The uncertainties associated with climate change projections are considerable, and there are a range of issues associated with their application. As a consequence, there is a need for:

- water managers, in dialogue with the hydrologists and climate scientists, to understand what can realistically be provided, the associated limitations and, in this light, to make best (and appropriate) use of what can be provided. This includes understanding that apparently precise projections (where detail is provided at fine spatial and temporal scales) are not necessarily any more accurate.

- climate scientists and hydrologists not to 'oversell' what they can provide (particularly given that it takes considerable resources to develop projections at fine spatial and temporal scales).

We would suggest that in any studies aimed at determining the impact of climate change on water resources and supplies, there needs to be a three-step process:

a. a clear articulation by water managers of what they need and what they would like;

b. a clear articulation by climate scientists/hydrologists of what is realistically possible and the associated uncertainties/limitations;

c. a dialogue between water managers and climate scientists/hydrologists aimed at determining how best to tailor outputs, and apply the projections, in the light of both (a) and (b).

Having gone through this process in the case of the runoff projections described above, it was deliberately decided not to become too precise in their application, with the projections having been provided for application as annual averages on a river basin basis. This is despite the fact that there has been significant interest from water corporations in obtaining data at more detailed spatial and temporal scales.

It has been made clear in the guidelines that the emphasis in planning must be precautionary and be based on developing robust and adaptive strategies that are capable of responding to a wide range of plausible water availability futures, and that are subject to regular review. The climate change projections described in this paper are important in helping define a realistic range of plausible climate/water availability futures.

However, importantly, this paper has shown one way in which close collaboration between climate scientists, hydrologists and water managers has led to water managers obtaining what they need (even if it is not exactly what they want) in order to be able to manage their water resources into the future in light of climate change.

\section{ACKNOWLEDGMENTS}

This work was supported by the South Eastern Australian Climate Initiative. 


\section{REFERENCES}

Beven, K. (2011). I believe in climate change but how precautionary do we need to be in planning for the future? Hydrol. Proc., 25(9): 1517-1520.

Chiew, F.H.S., Teng, J., Vaze, J., Post, D.A., Perraud, J.M., Kirono, D.G.C. and Viney, N.R. (2009). Estimating climate change impact on runoff across southeast Australia: Method, results, and implications of the modeling method. Water Resour. Res., 45(10): W10414.

CSIRO (2010a) Climate variability and change in south-eastern Australia: A synthesis of findings from Phase 1 of the South Eastern Australian Climate Initiative (SEACI), CSIRO, Australia. http://www.seaci.org/publications/documents/SEACI-1\%20Reports/Phase1_SynthesisReport.pdf.

CSIRO (2010b) South Eastern Australian Climate Initiative Program Annual Report 2009/10, CSIRO, Australia. http://www.seaci.org/publications/documents/SEACI-2Reports/S2_AR0910.pdf.

Frederiksen CS, Frederiksen JS, Sisson JM, Osbrough SL (2011) Australian winter circulation and rainfall changes and projections. Int. J. of Climate Change Strategies and Management (JCCSM), Paper 4, 3 (2).

IPCC (2007). Climate Change 2007: The Physical Science Basis. Contribution of Working Group I to the Fourth Assessment Report of the Intergovernmental Panel on Climate Change. In: Solomon, S. et al. (Eds.). Cambridge University Press, Cambridge, UK.

Jeffrey, S.J., Carter, J.O., Moodie, K.B. and Beswick, A.R. (2001). Using spatial interpolation to construct a comprehensive archive of Australian climate data. Env. Model. Soft., 16(4): 309-330.

Kent D.M., Kirono D.G.K., Timbal B., Chiew F.H.S. (Submitted) The Australian sub-tropical ridge in the CMIP3 models. Submitted to Int. J. Climatol.

Kiem, A.S. and Verdon-Kidd, D.C. (2011). Steps toward useful hydroclimatic scenarios for water resource management in the Murray-Darling Basin. Water Resour. Res., 47: W00G06.

Kundzewicz, Z.W. and Stakhiv, E.Z. (2010). Are climate models "ready for prime time" in water resources management applications, or is more research needed? Hydrological Sciences Journal, 55(7): 1085 $-1089$.

Manning M.R., Edmonds J., Emori S., Grubler A., Hibbard K., Joos F., Kainuma M., Keeling R.F., Kram T., Manning A.C., Meinshausen M., Moss R., Nakicenovic N., Riahi K., Rose S.K., Smith S., Swart R. and van Vuuren D.P. (2010) Misrepresentation of the IPCC CO2 emission scenarios. Nature Geoscience, 3, June 2010 pp 376-377.

Moran, R.J. and Sharples J. (2011) Guidelines for the Development of a Water Supply-Demand Strategy: Technical Supplement for Section 3.5 "Forecasting Supply". Unpublished report for the Department of Sustainability and Environment, 110 pp.

Post, D.A., Teng, J., Chiew, F., Wang, B., Vaze, J. and Marvanek, S. (2011). Non-linearity of the runoff response across south-eastern Australia to increases in global average temperature, Hydroclimatology: Variability and Change. IAHS Publication 344. IAHS Press, Wallingford, UK, pp. 188-194.

Post, D.A., Chiew, F.H.S., Teng, J., Viney, N.R., Ling, F.L.N., Harrington, G., Crosbie, R.S., Graham, B., Marvanek, S. and McLoughlin, R. (In Press). A robust methodology for conducting large-scale assessments of current and future water availability and use: A case study in Tasmania, Australia. J. Hydrol. doi: 10.1016/j.jhydrol.2011.02.011.

Sun, F., Roderick, M.L., Lim, W.H. and Farquhar, G.D. (2011). Hydroclimatic projections for the MurrayDarling Basin based on an ensemble derived from Intergovernmental Panel on Climate Change AR4 climate models. Water Resour. Res., 47: W00G02.

Vaze, J., Davidson, A., Teng, J. and Podger, G. (2011). Impact of climate change on water availability in the Macquarie-Castlereagh river basin in Australia. Hydrol. Proc. 25(16):2597-2612.

Vaze, J. and Teng, J. (2011). Future climate and runoff projections across New South Wales, Australia: results and practical applications. Hydrol. Proc., 25(1): 18-35.

Viney, N.R., Vaze, J., Chiew, F.H.S., Perraud, J.M., Post, D.A. and Teng, J. (2009). Comparison of multimodel and multi-donor ensembles for regionalisation of runoff generation using five lumped rainfall-runoff models, MODSIM 2009 International Congress on Modelling and Simulation. MSSANZ, Cairns, Australia, pp. 3428-3434. 